idaea L. and Calluna vulgaris L. In early June 2000, the trees on three plots were girdled at $1.5-\mathrm{m}$ above ground, by complete removal of the bark over $0.3-\mathrm{m}$ long sections around the circumferences of the stems (early girdled plots). In mid-August 2000, we girdled the trees on three other plots (late girdled plots). On both occasions, it took 2 people 4 days to girdle all $(\sim 360)$ the trees. Three plots of ungirdled trees were used as controls throughout the experiment. Air temperature, soil temperature at $5-\mathrm{cm}$ soil depth in the mineral soil, and precipitation were measured continuously at a standard meteorological station in an open field $150 \mathrm{~m}$ from the centre of the experiment (Fig. 1c). On one early girdled, one late girdled and one control plot, sensors below the organic mor layer (4-cm deep) recorded soil temperatures continuously (Fig. 1c). This, and more detailed measurements of surface soil temperatures and gravimetric soil moisture contents revealed no changes in response to the girdling treatments during the period of study.

\section{Analysis of soil respiration}

Soil respiration was measured as described previously ${ }^{17}$ on nine occasions during June to October. Within $1 \mathrm{~m}$ of the centre of each plot, three $0.0464-\mathrm{m}^{2}$ plastic cylinders were placed on the ground before measurements, the superficial layer of lichens, mosses and litter was temporarily removed, and a lid was placed on each cylinder to form a 6-1 headspace. Starting $2 \mathrm{~min}$ after the lid was put on, five 12-ml gas samples were removed by a syringe through a rubber membrane in the lid at 2-min intervals. At the two last sampling times, when soil respiration rates were low, the intervals between samples was $4 \mathrm{~min}$. Gas samples were transferred to pre-evacuated vials, which were analysed for their contents of $\mathrm{CO}_{2}$ on a gas purification module coupled on-line to an isotope-ratio mass spectrometer ${ }^{17}$ The rate of $\mathrm{CO}_{2}$ evolution from the soil was calculated by linear regression. In mid-August, 2-3 days after the last girdling and during the optimal period of fruiting, sporocarps of fungi were collected from the ground in the central $100-\mathrm{m}^{2}$ area of each plot. These were identified by species, and classified into two functional categories, ectomycorrhizal or saprotrophic. The number of species, the number of sporocarps, and their total dry biomass was determined. We sampled roots for starch analysis on three occasions (Table $1 \mathrm{~b})$. Fine $(<2 \mathrm{~mm}$ diameter) roots of $P$. sylvestris were extracted from auger samples taken just outside the central $100-\mathrm{m}^{2}$ plots, dried $\left(70^{\circ} \mathrm{C}, 48 \mathrm{~h}\right)$ and analysed for $\operatorname{starch}^{18}$. For comparisons among treatments, we used plot mean values. In calculations of the contribution of root respiration to total soil respiration, we used treatment mean values.

Received 1 December 2000; accepted 29 March 2001

1. Grace, J. \& Rayment, M. Respiration in the balance. Nature 404, 819-820 (2000)

2. Hanson, P. J., Edwards, N. T., Garten, C. T. \& Andrews, J. A. Separating root and soil microbial contributions to soil respiration: a review of methods and observations. Biogeochemistry 48, 115-146 (2000).

3. Malhi, Y., Baldocchi, D. D. \& Jarvis, P. G. The carbon balance of tropical, temperate and boreal forests. Plant Cell Environ. 22, 715-740 (1999).

4. Valentini, R. et al. Respiration as the main determinant of carbon balance in European forests. Nature 404, 861-865 (2000).

5. Goulden, M. L. et al. Sensitivity of boreal forest carbon balance to soil thaw. Science 279, 214-216 (1998).

6. Lindroth, A., Grelle, A. \& Morén, A. S. Long-term measurements of boreal forest carbon balance reveal large temperature sensitivity. Global Change Biol. 4, 443-450 (1998).

7. Post, W. M., Emanuel, W. R., Zinke, P. J. \& Stangenberger, A. G. Soil carbon pools and world life zones. Nature 298, 156-159 (1982)

8. Smith, S. E. \& Read, D. J. Mycorrhizal Symbioses 2nd edn (Academic, San Diego, 1997).

9. Söderström, B. \& Read, D. J. Respiratory activity of intact and excised ectomycorrhizal mycelial systems growing in unsterile soil. Soil Biol. Biochem. 19, 231-236 (1987).

10. Hansen, J., Türk, R., Vogg, G., Heim, R. \& Beck, E. in Trees—Contributions to Modern Tree Physiology (eds Rennenberg, H., Eschrich, W. \& Ziegler, H.) 97-108 (Backhuys, Leiden, 1997)

11. Ericsson, A. \& Persson, H. Seasonal changes in starch reserves and growth of fine roots of 20-year-old Scots pines. Ecol. Bull. 32, 239-250 (1980).

12. Plamboeck, A. H., Grip, H. \& Nygren, U. A hydrological tracer study of water uptake depth in a Scots pine forest under two different water regimes. Oecologia 119, 452-460 (1999).

13. Ågren, G. I. et al. Annual carbon budget for a young Scots pine. Ecol. Bull. 32, 307-313 (1980).

14. Edwards, N. T. \& Ross-Todd, B. M. The effects of stem girdling on biogeochemical cycles within a mixed deciduous forest in eastern Tennessee. I. Soil solution chemistry, soil respiration, litterfall and root biomass studies. Oecologia 40, 247-257 (1979).

15. Boone, R. D., Nadelhoffer, K. J., Canary, J. D. \& Kaye, J. P. Roots exert a strong influence on the temperature sensitivity of soil respiration. Nature 396, 570-572 (1998).

16. Craine, J. M., Wedin, D. A. \& Chapin, F. S. III. Predominance of ecophysiological controls on soil $\mathrm{CO}_{2}$ flux in a Minnesota grassland. Plant Soil 207, 77-86 (1999).

17. Högberg, P. \& Ekblad, A. Substrate-induced respiration measured in situ in a $\mathrm{C}_{3}$-plant ecosystem using additions of $\mathrm{C}_{4}$-sucrose. Soil Biol. Biochem. 28, 1131-1138 (1996).

18. Steen, E. \& Larsson, K. Carbohydrates in roots and rhizomes of perennial grasses. New Phytol. 104, 339-346 (1986).

\section{Acknowledgements}

We gratefully acknowledge funding by the EU to P.H. and D.J.R. through the project FORCAST, by the Swedish Natural Sciences Research Council and Swedish National Energy Administration to P.H. and by the European Science Foundation to N.B. (LINKECOL); chemical analyses by A. Ohlsson and L. Skoglund; and technical assistance by G. Moen and L. Ohlsson.

Correspondence and requests for materials should be addressed to P.H (e-mail: Peter.Hogberg@sek.slu.se).

\section{Proximity signal and shade avoidance differences between early and late successional trees}

\author{
Ian R. Gilbert ${ }^{\star}$ Paul G. Jarvis $\uparrow$ \& Harry Smith $\ddagger$
}

${ }^{\star}$ Institute of Cell and Molecular Biology; and $\dagger$ Institute of Ecology and Resource Management, University of Edinburgh, Edinburgh, EH9 3JU, UK

$\$$ Division of Plant Science, University of Nottingham, Sutton Bonington Campus, Loughborough LE12 5RD, UK

Competitive interactions between plants determine the success of individuals and species. In developing forests, competition for light is the predominant factor. Shade tolerators acclimate photosynthetically to low light ${ }^{1-3}$ and are capable of long-term survival under the shade cast by others, whereas shade avoiders rapidly dominate gaps but are overtaken in due course by shade-tolerant, later successional species. Shade avoidance ${ }^{4-6}$ results from the phytochrome-mediated perception of far-red radiation (700$800 \mathrm{~nm}$ ) scattered from the leaves of neighbours, provides early warning of shading ${ }^{7}$, and induces developmental responses that, when successful, result in the overgrowth of those neighbours ${ }^{8}$. Shade tolerators cast a deep shade, whereas less-tolerant species cast light shade', and saplings tend to have high survivorship in shade cast by conspecific adults, but high rates of mortality when shaded by more-tolerant species ${ }^{9}$. Here we report a parallel relationship in which the shade-avoidance responses of three tree species are inversely proportional to proximity signals generated by those species. On this basis, early successional species generate small proximity signals but react strongly to them, whereas late successional species react weakly but generate strong signals.

Shade-avoiding plants respond to the relative amounts of red $(\mathrm{R} ; 600-700 \mathrm{~nm})$ and far-red (FR; 700-800 $\mathrm{nm}$ ) photons in incident radiation by establishing different concentrations of the active 'Pfr' form of the phytochromes ${ }^{10}$. For many plants, the elongation growth rate of the stems bears an inverse linear relationship to the established concentration of $\mathrm{Pfr}$, which is usually expressed as the proportion of total phytochrome (P) that is present as $\mathrm{Pfr}$ (that is, the photoequilibrium or $\mathrm{Pfr} /$ $\mathrm{P})^{11,12}$. The slope of this relationship may be regarded as the 'shade avoidance response sensitivity'. This varies between species, with strong shade avoiders presenting a steep slope and weak shade avoiders presenting a shallow slope ${ }^{13}$. In addition, different species have different intrinsic elongation growth rates. These elements-intrinsic elongation rate and response sensitivity-combine to describe the overall shade avoidance response of plants in the natural environment. To explain the dynamics of tree growth in developing canopies, we sought to identify and quantify both intrinsic growth rates $\left(R_{\mathrm{i}}\right)$ and response sensitivities $(S)$ of tree species with contrasting growth dynamics.

We grew stands of tree species at different spacings, and measured height growth, leaf area, leaf distribution and within-canopy radiation environment throughout several growing seasons. Three species of contrasting growth habits and leaf morphology were studied-Acer pseudoplatanus (a late successional species known as sycamore in the UK and sycamore-maple in North America), Betula pendula (silver birch, an early successional species) and Populus deltoides $\times$ trichocarpa cv. Beaupré (a hybrid poplar bred for rapid elongation growth). These species were grown in both pure stands (that is, single species) or in mixed stands that included another species, Salix viminalis (osier willow), chosen because it is a shrubby species with dense leaf coverage of stems and thereby 
generates strong proximity signals. The stands were rectangular grid arrays of differing spacings. Replicated monitoring over several years provided mean growth data from which the response parameters were derived. Radiation measurement was centred on selected 'target trees' and consisted of spectroradiometric measurements of $\mathrm{R}$ and FR radiation propagated roughly horizontally at different heights in the stands ${ }^{12}$.

Height growth rate of the three species grown in pure stands increased as tree density increased (Fig. 1a), as did effects on the spectral distribution of the radiation that was propagated nearhorizontally in the canopy, with a consequent depression of the R:FR ratio and thus of the calculated Pfr/P (Fig. 1b). All species reacted to neighbours by increased elongation growth, but the three species had different intrinsic growth rates. The slopes of the relationships between height growth rate and plant density, however, were not markedly different. The three species had differential effects on the radiation environment, with A. pseudoplatanus depressing $\mathrm{Pfr} / \mathrm{P}$ the most and $B$. pendula the least. In other words, the late successional species generated strong proximity signals, whereas the early successional species generated weak signals.

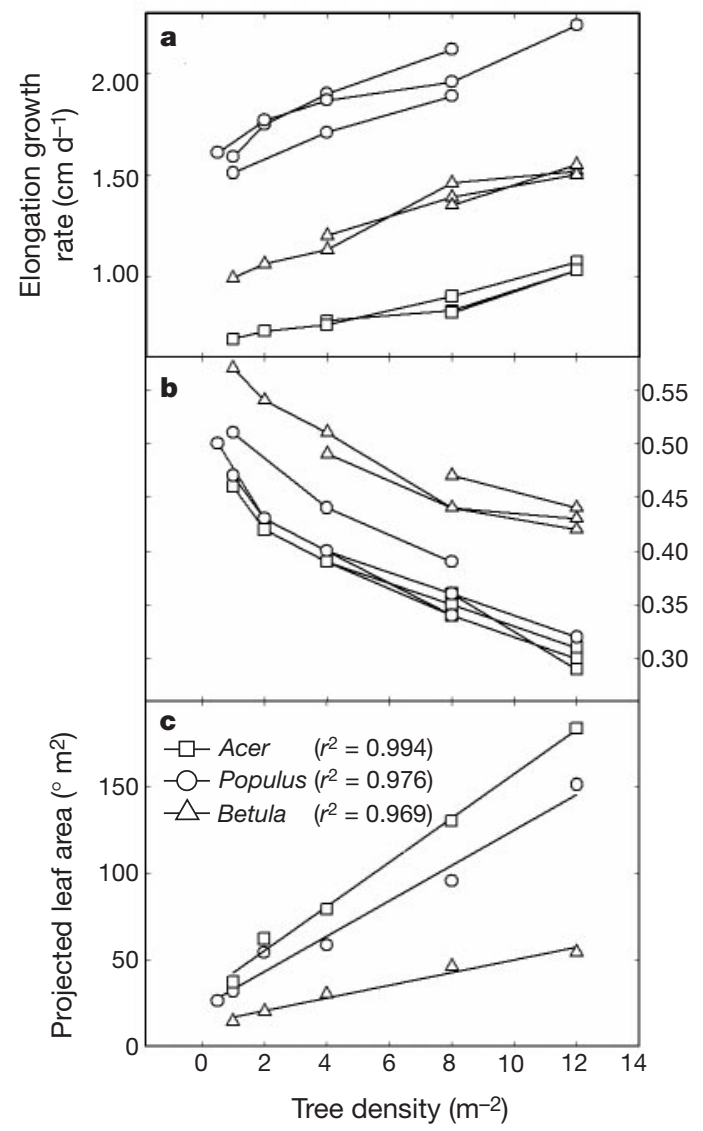

Figure 1 Relationships between planting density and tree height growth, within-canopy radiation environment and intensity of proximity signals. Pure stands of the three species were grown in regular grids at the stated planting densities. The radiation propagated horizontally at the central target tree was monitored with a spectroradiometer and the data converted to a value of expected phytochrome photoequilibrium ( $\mathrm{Pfr} / \mathrm{P}$, where $\mathrm{Pfr}$ represents the amount of Pfr present at photoequilibrium and $P$ represents the total phytochrome). a, Mean height growth over 120 days, from day 140 (20 May) to day 260 (17 September). b. Minimum photoequilibria recorded at day 220 (8 August), for each of three growing seasons. c, Intensity of reflection signals is a species-specific function of planting density. Mean data for projected leaf area were calculated from detailed measurements of four representative trees at each planting density. Lines are simple regression lines.
We obtained linear relationships when the tree data were replotted against $\mathrm{Pfr} / \mathrm{P}$ (Fig. 2). The relationships include data from the final year of experimentation, in which we grew mixed plots at the two highest tree densities (black symbols). For A. pseudoplatanus and Populus cv. Beaupré, the mixed plot data lie within the ranges of $\mathrm{Pfr} / \mathrm{P}$ obtained in pure stands of those species. By contrast, for $B$. pendula the mixed plot data show that the relationship extends beyond that obtained with the pure stands, which had much smaller effects on the R:FR ratio. In other words, $B$. pendula trees have stronger shade avoidance responses in stands with other species than in conspecific stands.

Figure 2 shows that the state of phytochrome regulates elongation growth in the three species in a very similar manner; thus, the elongation response of the target trees is determined solely by the effect of incoming radiation on the concentration of Pfr. Even so, the shade avoidance reactions of the three species in the plots were quite different, and consequently other factors, related to, or consequent on, the radiation signal must also determine the response. We reasoned that the element in the canopies that generates the radiative signal is likely to be the quantity of plant material, particularly the surface area of the leaves, that scatters FR radiation within the range of perception of the target tree, thereby generating proximity signals. Consequently, we calculated an effective radiation scattering quantity - called the 'projected leaf area' (PLA) - in each canopy established in these experiments. The calculation is facilitated by the regular grid pattern of the trees and by the limitation of each tree to a single main stem. The elements of the calculation are number of leaves, vertical distribution of leaf area, spatial distribution of leaf inclination, azimuth and zenith angles, and effective tree width and height (see Methods). We calculated PLA for the different species and densities using detailed measurements of four representative trees selected randomly in each plot, using a target tree at the centre of each stand.

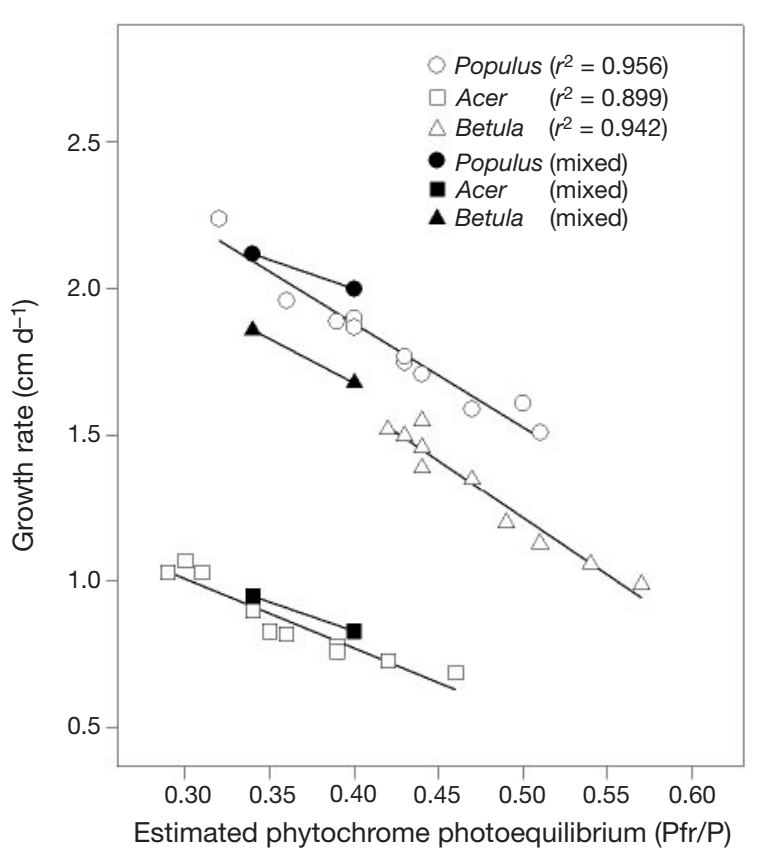

Figure 2 Height growth rate is a direct function of estimated phytochrome photoequilibrium. Data for the pure stands of single species (open symbols) and the mixed stands of all four species (closed symbols) are presented to show the linear relationships between phytochrome photoequilibrium estimated from the within-canopy radiation environment and tree height growth rate. Lines shown for the pure stands are regression lines for all annual data for each species; mixed plots at 8 and 12 trees per $\mathrm{m}^{2}$ are separate lines connecting the two data items in each case. 
Figure 1c shows the relationships between tree density and PLA for the three species. In each case, there was an increase in PLA with increasing stand density of trees. The largest values of PLA were observed with A. pseudoplatanus and the smallest with B. pendula. This relates well to the large leaves of the former, which are densely distributed along the main axis $\left(35 \mathrm{~cm}^{2}\right.$ of leaf area per $\mathrm{cm}$ of stem length), in contrast to the small leaves of the latter, which are scattered more thinly throughout the tree canopy $\left(7 \mathrm{~cm}^{2}\right.$ of leaf area per $\mathrm{cm}$ of stem length).

Figure 3 confirms that PLA calculated as above is related to the strength of the proximity signal. We plotted PLA against Pfr/P estimated from spectroradiometric measurements of the radiation reaching the target trees. Over a very wide range, including both the pure stands and the mixed plots of all four species, $\mathrm{Pfr} / \mathrm{P}$ was linearly related to the logarithm of PLA. These data relate the radiation signals received by the target tree to those generated by its neighbours. We draw the conclusion that leaves of the different species, irrespective of their detailed optical properties, have essentially the same effect on the R:FR radiation environment. On this basis, PLA provides a measure of the proximity signal generated by neighbours and received by a target tree in a stand of trees. Projected leaf area is therefore an effective estimate of the capacity of a tree to generate radiation signals as a function of leaf area density. We generated Fig. 4 by plotting elongation growth rate against PLA, using all the available data. This depicts the shade avoidance capacity of the three species by relating the scale of response to the source of the signalthat is, to the amount of leaf material scattering radiation in the perception range of the target tree.

Using Fig. 4, we calculated $R_{\mathrm{i}}$ from the $y$-axis intercepts and $S$ from the slopes of the lines. Table 1 shows that $A$. pseudoplatanus has a low intrinsic elongation rate and a small response sensitivity to proximity signals. A. pseudoplatanus is generally regarded as a late successional tree, capable of substantial shade tolerance. Eleven species of maple in North American forests were shown to be shade tolerant and did not show shade avoidance responses in gap-edge situations ${ }^{14}$. By contrast, $B$. pendula is an early successional species, with a low intrinsic elongation rate but a very high capacity to respond to radiation signals. On this basis, $B$. pendula is more than five times as responsive as A. pseudoplatanus. The hybrid Populus cultivar Beaupré, bred for high productivity, has a high intrinsic growth rate but shade avoidance sensitivity intermediate between that of $A$. pseudoplatanus and B. pendula.

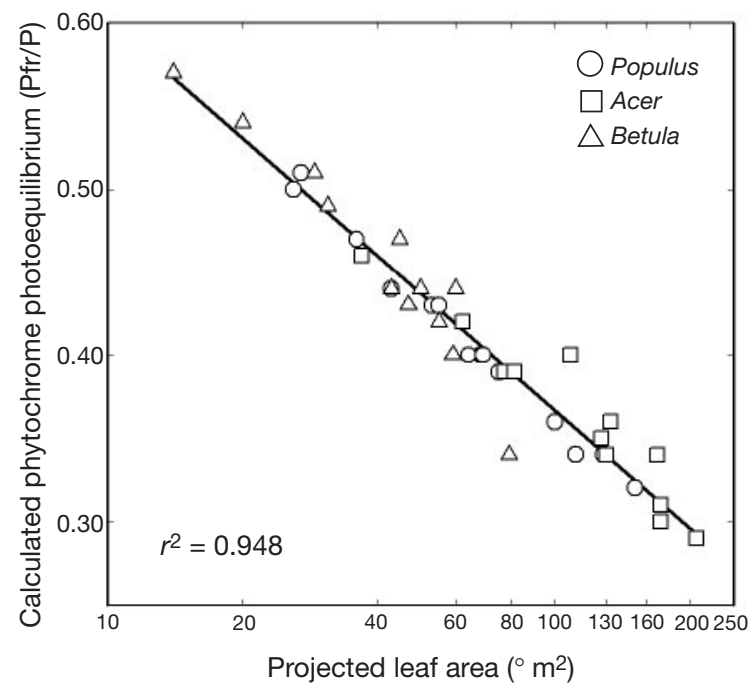

Figure 3 Projected leaf area is an accurate estimate of proximity signals. Estimated Pfr/P ratio established by the radiation reaching the target tree is shown to bear a close logarithmic relationship to projected leaf area.

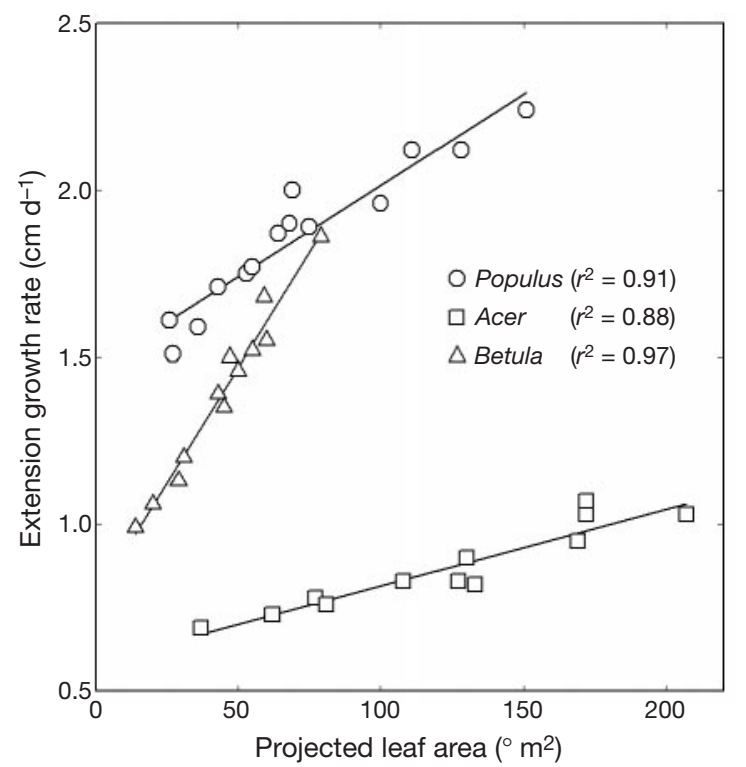

Figure 4 Projected leaf area has a species-specific relationship to the height growth rates of the three species. Data drawn from all annual trials, including both pure and mixed plots.

Shade avoidance has major fitness attributes in crowded communities, but may be disadvantageous for some species in that it results in the allocation of resources to stem growth ${ }^{15}$ and away from storage and reproductive structures. For late successional trees such as A. pseudoplatanus, the large leaves and dense canopy effectively generate strong FR proximity signals. Under the circumstances of these experiments, A. pseudoplatanus, which is generally regarded as shade tolerant, showed shade avoidance responses over a wide range of PLA, but the sensitivity of response to such signals was low. $B$. pendula, an early successional tree, has sparsely distributed small leaves and generates weak proximity signals, although it responds strongly to such signals. If FR proximity signals are indicators of impending competition for radiant energy ${ }^{7}$, then $B$. pendula has the capacity to respond well to competition but generates only small radiation signals itself. Thus, $B$. pendula seedlings appearing in an established A. pseudoplatanus woodland would experience strong proximity signals and exhibit shade avoidance responses that would be maladaptive. In a gap, however, emerging $B$. pendula seedlings, with a higher intrinsic elongation rate than that of $A$. pseudoplatanus seedlings and with a strong response to even weak proximity signals, would be well-equipped to colonize the gap, at least temporarily. Ultimately, the shade-tolerance of $A$. pseudoplatanus, plus its parsimonious intrinsic elongation rate, would allow it to survive under the light shade cast by $B$. pendula.

We conclude that the morphology and size of leaves, and their distribution in relation to height in the canopy, are highly significant in the competition for living space that exists at all times

\begin{tabular}{|c|c|c|c|}
\hline Species & $\begin{array}{c}\text { Intrinsic } \\
\text { elongation rate } \\
\left(R_{\mathrm{i}}\right)\end{array}$ & $\begin{array}{c}\text { Shade avoidance } \\
\text { sensitivity } \\
\text { (S) }\end{array}$ & Relative sensitivity \\
\hline Acer & 0.58 & 0.0024 & 1 \\
\hline Betula & 0.78 & 0.0138 & 5.75 \\
\hline Populus & 1.47 & 0.0055 & 2.29 \\
\hline
\end{tabular}

Intrinsic elongation growth rates $\left(\mathrm{cm} \mathrm{d}^{-1}\right)$ were calculated from the intercepts of the regression lines in Fig. 4 with a value of zero for RLA. Shade avoidance response sensitivities were calculated from the slopes of the respective regression lines in Fig. $4 \mathrm{~b}$. 
between plants growing in crowded communities - both in terms of generating proximity signals and in terms of the capacity for shade tolerance. These data provoke speculation that there may be an evolutionary trade-off between the morphology, architecture and growth pattern of a shade tolerator and those of a shade avoider.

\section{Methods}

\section{Planting materials and growth of canopies}

This research was carried out at the University of Leicester, UK. Betula pendula saplings were obtained, with permission, from a reserve run by the Royal Society for the Protection of Birds at Brampton, Northumbria, UK (grid reference NY587655). A. pseudoplatanus saplings were obtained, with permission, from Priory Wood—a designated 'site of special scientific interest' (SSSI) in Leicestershire, UK (grid reference SK498109). The S. viminalis plants were grown from stem cuttings taken originally (1971) from a clonal coppice stand in south Nottinghamshire, UK, by H.S. Hybrid $P$. deltoides $\times$ trichocarpa cv. Beaupré were from the Institute of Terrestrial Ecology, Penicuik, UK. Trees were grown in 10- $\mathrm{dm}^{3}$ pots irrigated individually, and top dressed in early spring and summer with $10 \mathrm{~g}$ of Osmocote Plus (15:11:13) and $5 \mathrm{~g}$ of Greenmaster Super-N (24:0:0). We arranged pots in stands of 1 , 2, 4,8 and 12 pots per $\mathrm{m}^{2}$ either on the roof of the Biological Sciences building or at the University of Leicester Botanic Gardens, and grew them for at least three seasons. All trees were pruned as they grew to remove laterals to keep the three-dimensional geometry of the plants simple and to minimize azimuthal effects. Data for tree height, tree width, numbers of leaves and leaf area were recorded throughout the growing seasons. Leaf areas were estimated from a programme of detailed measurements in mid-season near day 220 (8 August). All the above variables were measured for eight trees in each plot, except for the detailed leaf measurements, for which only four trees were measured.

\section{Radiation environment}

For all canopies, a central 'target tree' was selected, and the radiation that propagated more or less horizontally within the canopy and reached the tree was monitored throughout the seasons. Horizontal narrow angle sensors $\left(10^{\circ} \times 180^{\circ}\right.$ letterbox $)$, placed at six pre-selected height positions at the target tree, piped radiation along fibre-optic bundles to a selector wheel and then to a spectroradiometer (Licor LI-1800; Lincoln, NV, USA). We collected data every $10 \mathrm{~min}$, giving a complete set of readings for the six height positions during daylight hours ${ }^{12}$. Spectral photon flux data were converted into estimated phytochrome photoequilibrium $(\mathrm{Pfr} / \mathrm{P})$ by integrating the absorption cross-sections of $\mathrm{Pr}$ and $\mathrm{Pfr}$ with the spectral photon flux distributions of the incident radiation across the $400-800-\mathrm{nm}$ waveband ${ }^{16}$.

\section{Calculation of projected leaf area}

Projected leaf area (PLA) is an estimate of the total leaf area in the neighbourhood of the target tree that is capable of scattering radiation towards the target tree. To estimate PLA, we measured leaf position (that is, height above ground), leaf area and leaf angles

(azimuth, inclination and zenith angles) for four randomly selected signal trees in each plot, and obtained estimates of the means from these. For each leaf distributed along a tree axis, the height and angle data were used to calculate the area projected by the leaf onto a cylinder representing the tree surface, itself calculated from tree height and average crown diameter. The total of the projected areas for all leaves on the tree was divided by the total area of the cylinder surface, and this ratio was used to calculate occlusion of the signal by intervening trees. The occlusion of the signal from distant trees by nearer trees was calculated geometrically using the grid of the planting design. The reduction of signal with tree distance was calculated as a function of the angular wedge subtended by a tree cylinder to the stem of the target tree. PLA represents the arithmetic sum of all signals, corrected for occlusion and for distance. The units of PLA are degrees $\times$ area $\left({ }^{\circ} \mathrm{cm}^{2}\right)$.

Received 22 February; accepted 3 April 2001

1. Boardman, N. K. Comparative photosynthesis of sun and shade plants. Annu. Rev. Plant Physiol. 28 355-377 (1977).

2. Bjørkman, O. in Encyclopaedia of Plant Physiology Vol. 12.4 (eds Lange O. L., Nobel, P. S., Osmond, C. B. \& Ziegler, H.) 57-107 (Springer, Berlin, 1981).

3. Kull, $\mathrm{O} \&$ Niinemets, U. Distribution of leaf photosynthetic properties in tree canopies: comparison of species with different shade tolerance. Funct. Ecol. 12, 472-479 (1998).

4. Smith, H. Light quality, photoperception and plant strategy. Annu. Rev. Plant Physiol. 33, 481-518 (1982).

5. Smith, H. Physiological and ecological function within the phytochrome family. Annu. Rev. Plant Physiol. Plant Mol. Biol. 46, 289-315 (1995).

6. Smith, H. Phytochromes and light signal perception by plants—an emerging synthesis. Nature 407, 585-591 (2000).

7. Ballare, C. L., Scopel, A. L. \& Sanchez, R. A. Far-red radiation reflected from adjacent leaves: an early signal of competition in plant canopies. Science 247, 329-332 (1990).

8. Casal, J. J. \& Smith, H. The function, action and adaptive significance of phytochrome in light-grown plants. Plant Cell Environ. 12, 855-862 (1989).

9. Canham, C. D., Finzi, A. C., Pacala, S. W. \& Burbank, D. H. Causes and consequences of resource heterogeneity in forests-interspecific variation in light transmission by canopy trees. Can. J. Forest Res. 24, 337-349 (1994).

10. Smith, H. \& Holmes, M. G. The function of phytochrome in the natural environment. III.
Measurement and calculation of phytochrome photoequilibrium. Photochem. Photobiol. 25, 547-550 (1977).

11. Morgan, D. C. \& Smith, H. Linear relationship between phytochrome photoequilibrium and growth in plants under simulated natural radiation. Nature 262, 210-212 (1976).

12. Gilbert, I. R., Seavers, G. P., Jarvis, P. G. \& Smith, H. Photomorphogenesis and canopy dynamics. Phytochrome-mediated proximity perception accounts for the growth dynamics of canopies of Populus trichocarpa $\times$ deltoides 'Beaupré.' Plant Cell Environ. 18, 475-449 (1995).

13. Morgan, D. C., Smith, H. A systematic relationship between phytochrome-controlled development and species habitat for plants grown in simulated natural radiation. Planta 145, 253-259 (1979).

14. Lei, T. T \& Lechowicz, M. J. Diverse responses of maple saplings to forest light regimes. Am. J. Bot. 82, 9-19 (1998).

15. Child, R., Morgan, D. C. \& Smith, H. Control of development in Chenopodium album by shadelight: The effect of light quality (red:far-red ratio) on morphogenesis. New Phytol. 89, 545-555 (1981). 16. Hayward, P. M. in Techniques in Photomorphogenesis (eds Smith, H. \& Holmes, M. G.) 159-173 (Academic, London, 1984).

\section{Acknowledgements}

This research was funded by the Natural Environment Research Council, UK, and was made possible by the technical assistance of S. Smith, M. Pratt and G. Benskin.

Correspondence and requests for materials should be addressed to H.S.

(e-mail: Harry.Smith@Nottingham.ac.uk).

\section{Ant odometry in the third dimension}

\section{Sandra Wohlgemuth*, Bernhard Ronacher ${ }^{\star}$ \& Rüdiger Wehner $†$}

* Institute of Biology, Humboldt-University Berlin, Invalidenstrasse 43, D 10099 Berlin, Germany

$\dagger$ Department of Zoology, University of Zurich, Winterthurerstrasse 190, CH 8057 Zurich, Switzerland

Desert ants (Cataglyphis) are renowned for their ability to perform large-scale foraging excursions and then return to the nest by path integration. They do so by integrating courses steered and the distances travelled into a continually updated home vector ${ }^{1}$. Whereas the angular orientation is based on skylight cues ${ }^{2}$, how the ants gauge the distances travelled has remained largely unclear ${ }^{3,4}$. Furthermore, almost all studies on path integration in Cataglyphis $^{5,6}$, as well as in spiders ${ }^{7,8}$, rodents $^{9}$, and humans ${ }^{10,11}$, have aimed at understanding how the animals compute homebound courses in the horizontal plane. Here, we investigate for the first time how an animal's odometer operates when a path integration task has to be accomplished that includes a vertical component. We trained Cataglyphis ants within arrays of uphill and downhill channels, and later tested them on flat terrain, or vice versa. In all these cases, the ants indicated homing distances that corresponded not to the distances actually travelled but to the ground distances; that is, to the sum of the horizontal projections of the uphill and downhill segments of the ants' paths.

Saharan desert ants (Cataglyphis fortis) leave their underground colonies for distances of several hundred metres, winding their way in a tortuous search for food, but then return to their point of departure along an amazingly straight path ${ }^{5}$. They accomplish this task by integrating information about the angular and linear components of movement, information provided by a compass and an odometer. The compass, which exploits polarization and spectral gradients in the sky, has been studied in some behavioural and neurophysiological detail ${ }^{2,12}$, but attempts to unravel the ant's odometer have so far met with limited success. Self-induced visual flow might be used to some extent ${ }^{3}$, as in flying bees, in which the odometer depends mainly on flow-field information ${ }^{13-15}$. Walking desert ants, however, can do without it and can derive information about walking distances completely from proprioceptive inputs ${ }^{3,4}$. Here, we investigate how these ants measure travelling distances in undulating terrain. 